\title{
Pneumonia and pneumonia related mortality in patients with COPD treated with fixed combinations of inhaled corticosteroid and long acting $\beta 2$ agonist: observational matched cohort study (PATHOS)
}

Janson and colleagues have informed us of an error in the pico version of this Research paper, which is available online as the "Section PDF" and published in print (BMJ 2013;346:f3306, doi:10.1136/bmj.f3306). In the pico's table the mortality rates related to pneumonia for fluticasone/salmeterol and budesonide/formoterol were the wrong way round. They should have been 97 (3.5\%) in the fluticasone/salmeterol group and 52 $(1.9 \%)$ in the budesonide/formoterol group (not the reverse, as was published).

Cite this as: BMJ 2013;346:44375

๑ BMJ Publishing Group Ltd 2013 